\title{
A retrospective comparative study of feto-maternal outcome in first and second stage caesarean section
}

\author{
Nidhi Jain ${ }^{1 *}$, Prabha Lal ${ }^{2}$ \\ ${ }^{1}$ Department of Gynaecology Endoscopy, Manchanda's Endoscopic centre, Delhi, India \\ ${ }^{2}$ Department of Obstetrics and Gynaecology, Lady Hardinge Medical College, Delhi, India
}

Received: 10 May 2016

Accepted: 03 June 2016

\section{*Correspondence:}

Dr. Nidhi Jain,

E-mail: nidhijain270587@gmail.com

Copyright: $\odot$ the author(s), publisher and licensee Medip Academy. This is an open-access article distributed under the terms of the Creative Commons Attribution Non-Commercial License, which permits unrestricted non-commercial use, distribution, and reproduction in any medium, provided the original work is properly cited.

\begin{abstract}
Background: The incidence of caesarean section has increased tremendously over the recent years. The most common indications of caesarean section are fetal distress and previous caesarean section during first stage caesarean section and cephalo-pelvic disproportion and fetal distress during second stage caesarean section. The objective of this study was to compare maternal and fetal outcomes between first and second stage caesarean section.

Methods: A retrospective cohort study was carried out in the department of obstetrics and gynaecology at a tertiary hospital over a period of 6 months. Comparison was done between two groups, women who underwent caesarean section during first stage (group I) and during second stage (group II). Data was collected and compared on basis of maternal and fetal outcomes.

Results: Among maternal complications, PPH occurred in significantly higher number of women in group II (21\%) than in group I (9\%). $21 \%$ of women in group II required blood transfusion and $7 \%$ admitted to ICU. Bladder injury and uterine incision extension was seen in more number of cases in group II ( $6 \%$ and $7 \%$ respectively), difference being statistically insignificant. Neonatal complications were significantly higher in group II.

Conclusions: Second stage caesarean sections are associated with significant maternal and fetal morbidities, thus necessitating presence of senior obstetrician at time of decision and conductance of procedure.
\end{abstract}

Keywords: Caesarean, First stage, Perinatal outcome, Retrospective study, Second stage

\section{INTRODUCTION}

The incidence of caesarean section has increased tremendously over the recent years. The most common indications of caesarean section are fetal distress and previous caesarean section during first stage caesarean section and cephalo-pelvic disproportion and fetal distress during second stage caesarean section. ${ }^{1}$ Over the years, second stage caesarean section rate have also risen immensely with decreasing trend of assisted vaginal delivery. Second stage caesarean section is difficult procedure as it is associated with deeply engaged head, less liquor and thinned out lower uterine segment, thus leading to high risk of maternal morbidity, such as tearing of the lower uterine segment, extension of the uterine incision and injury to urinary bladder as well as neonatal morbidity such as birth asphyxia, hypoxic ischemic encephalopathy and even neonatal death. ${ }^{2}$ Hence, this study is being done to compare maternal and fetal morbidities among women undergoing caesarean section during first stage and second stage of labour.

\section{METHODS}

This retrospective cohort study was carried out in the department of obstetrics and gynaecology at a tertiary hospital over a period of 6 months, after clearance from institutional ethical committee. Inclusion criteria were women with singleton pregnancy at term gestation (> 37 weeks). Exclusion criteria were multiple pregnancy, 
preterm gestation and previous caesarean section. The data was collected in form of demographic profile, obstetric history, labour characteristics, indication of caesarean section and complications observed during caesarean section. Comparison was done between two groups, first stage caesarean section (group I) and second stage caesarean section (group II). Observations were evaluated for maternal and fetal outcomes. P value $<0.05$ was considered significant.

\section{RESULTS}

During this study period of 6 months, total 8095 deliveries were conducted at our hospital i.e. around 45 deliveries per day. Emergency caesarean section was done in 1452 cases $(17.9 \%)$. The incidence of first stage and second stage caesarean section was $18.5 \%$ (1500) and $4 \%$ (324) respectively.

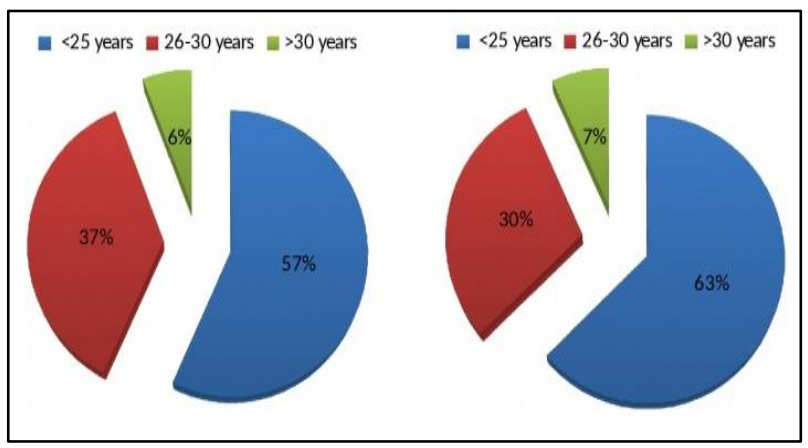

Figure 1: Pie chart showing distribution of women according to age in group I and group II.

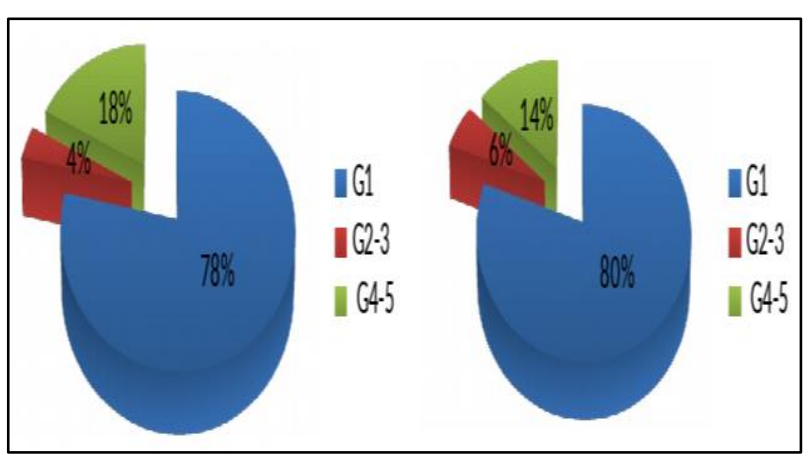

Figure 2: Pie chart showing distribution of women according to parity in group I and group II.

Among demographic profile, it was found that $57 \%$ women in group I and $63 \%$ in group II were young $(<25$ years), as shown in Figure 1. 78\% women in group I and $80 \%$ in group II were primigravida (Figure 2).

Among labour characteristics (as shown in Table 1), most of the women (83\% in group I and $87 \%$ in group II) had spontaneous onset of labour however most of them required oxytocin augmentation (81\% in group I and $86 \%$ in group II) for progress of labour.
The common indications of first stage caesarean section were fetal distress, non-progress of labour and failed induction. The most common indication of second stage caesarean section was deep transverse arrest (53\%), followed by feto-pelvic disproportion (47\%) and obstructed labour $(11 \%)$. The decision delivery time was more in group II (2.2 hours) than in group I (1.1 hours). Mean operative time was significantly more in group II (81 minutes) as compared to group I (35 minutes) as second stage caesarean section is a difficult procedure.

Table 1: Labour characteristics of women undergoing caesarean section in first stage (group I) and second stage (group II).

\begin{tabular}{|lll|}
\hline Labour characteristics & Group I & Group II \\
\hline Onset of labour (spontaneous) & $83 \%$ & $87 \%$ \\
\hline Oxytocin augmentation & $81 \%$ & $86 \%$ \\
\hline Decision delivery time (hours) & 1.1 & 2.2 \\
\hline Mean operative time (minutes) & 35 & 81 \\
\hline Head delivery & & \\
\hline Patwardhan technique & 00 & $86 \%$ \\
\hline Cephalic & $100 \%$ & $14 \%$ \\
\hline
\end{tabular}

In majority of patients, during second stage caesarean section, deeply engaged head was found. Higher incidence of deeply engaged head during second stage caesarean section was probably due to cervical dystocia, deep transverse arrest due to occipito-posterior position and unanticipated CPD late in labor.

Deeply impacted head can be extracted by various methods, which includes delivering vertex by passing hand under head, dis-impaction of vertex by upward pressure of an assistant per vaginum and Patwardhan technique with back anterior and back posterior. The first two methods are associated with higher chances of colporrhexis, extension of uterine incision, traumatic PPH and fetal injuries. Thus, Patwardhan technique was introduced to reduce these complications rate, which was found to have less operative time, less extension of uterine incision and less blood loss and need for blood transfusion. ${ }^{3}$ In group II, $86 \%$ babies were delivered by Patwardhan technique.

\section{Patwardhan technique}

It was introduced by Patwardhan BD and Motashaw ND for delivering deeply impacted fetal head during second stage caesarean section. ${ }^{4}$ Steps of Patwardhan technique are as follows:

\section{For back anterior}

- Delivery of anterior shoulder: anterior arm is delivered first by hooking finger in the elbow (Figure 3).

- Delivery of posterior shoulder: assistant applies traction with rotation on the delivered anterior arm 
and the operating surgeon delivers posterior shoulder (Figure 4).

- Delivery of trunk: the operating surgeon introduces index and middle finger on either side of chest and delivers fetal trunk by flexion. Thus, first chest is delivered followed by abdomen and lastly, breech. Assistant applies fundal pressure simultaneously (Figure 5).

- Delivery of head: the operating surgeon lifts the baby by legs and thereby, delivers head (Figure 6) and thus the baby delivers by Patwardhan technique (Figure 7).

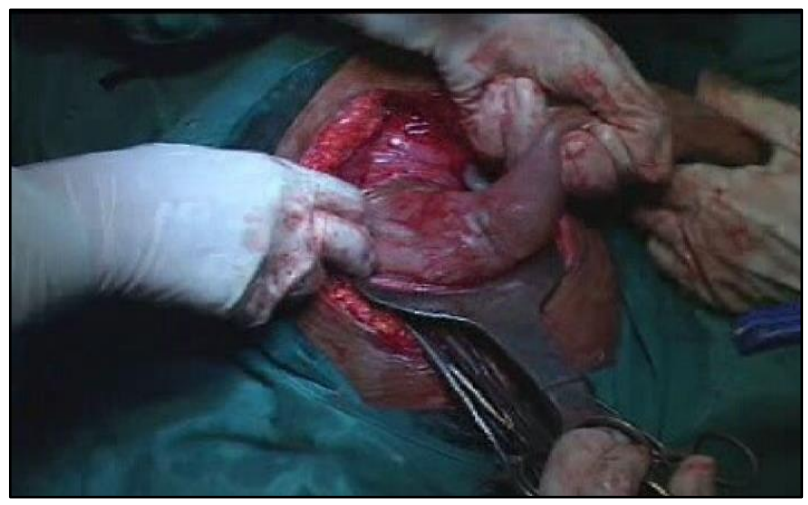

Figure 3: Patwardhan technique: delivery of anterior shoulder.

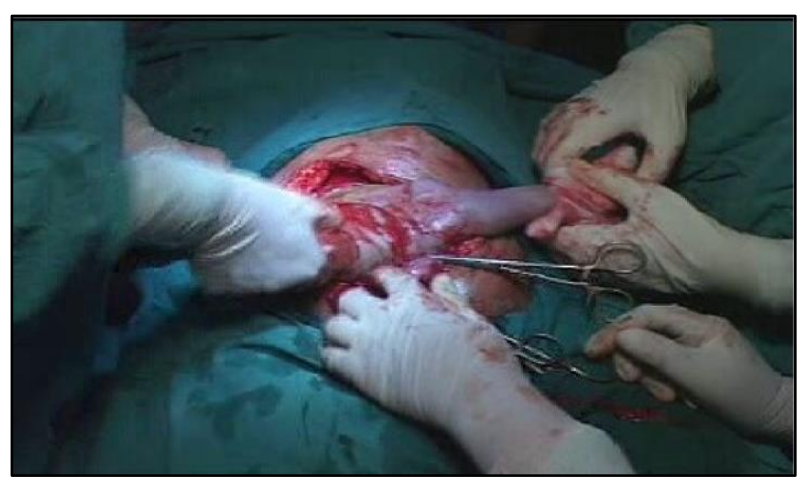

Figure 4: Patwardhan technique: delivery of posterior shoulder.

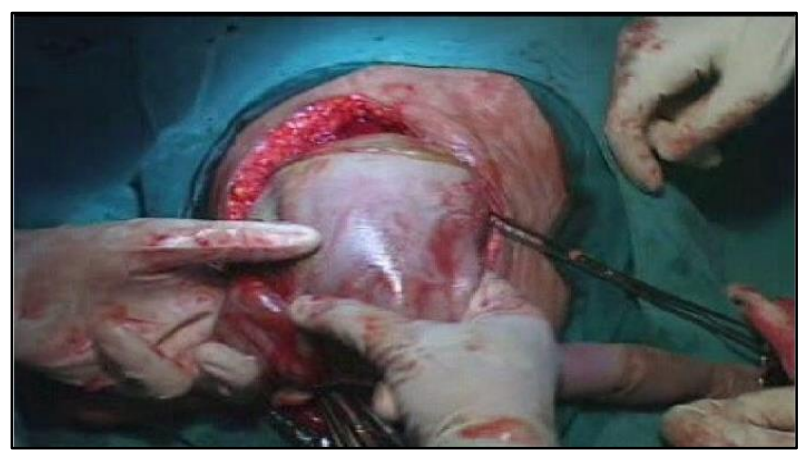

Figure 5: Patwardhan technique: delivery of trunk.

\section{For back posterior}

First available shoulder is delivered, followed by introduction of hand towards the fundus. Foot is gripped and gently pulled out. Assistant applies fundal pressure and thus, breech is delivered, after which head is delivered by lifting the legs.

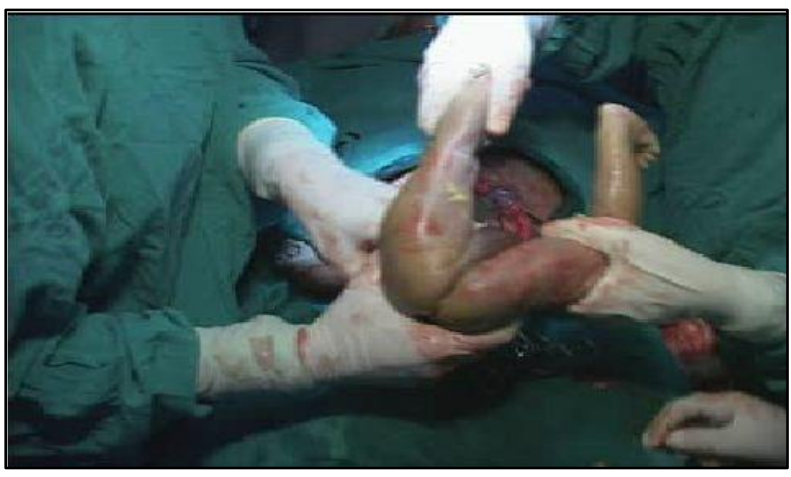

Figure 6: Patwardhan technique: delivery of head.

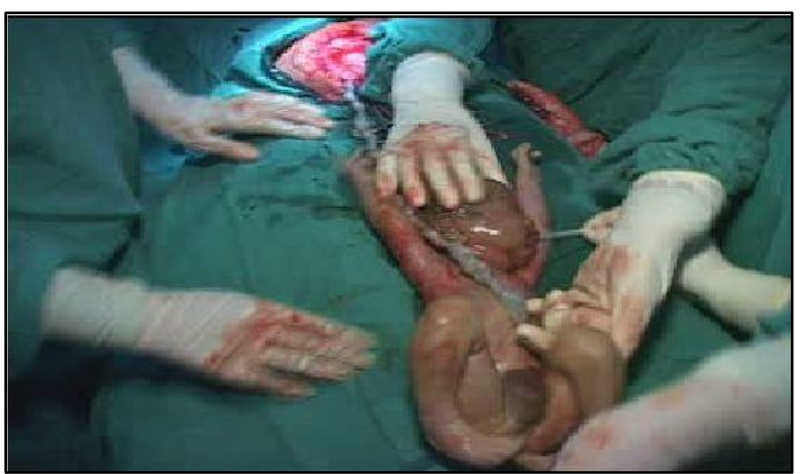

Figure 7: Baby delivered by Patwardhan technique.

\section{Maternal complications}

Table 2 and 3 shows the intra-operative and postoperative maternal complications observed in group I and II respectively.

Table 2: Comparison of intra-operative maternal complications associated with first stage caesarean section (group I) and second stage caesarean section (group II).

\begin{tabular}{|llll|}
\hline $\begin{array}{l}\text { Intra-operative } \\
\text { complications }\end{array}$ & $\begin{array}{l}\text { Group I } \\
(\% \text { of } \\
\text { women) }\end{array}$ & $\begin{array}{l}\text { Group II } \\
(\% \text { of } \\
\text { women) }\end{array}$ & $\begin{array}{l}\text { P } \\
\text { value }\end{array}$ \\
\hline PPH & $9 \%$ & $21 \%$ & \\
Atonic PPH & $4 \%$ & $16 \%$ & $<0.05$ \\
Traumatic PPH & $5 \%$ & $5 \%$ & \\
\hline Blood transfusion & $11 \%$ & $21 \%$ & 0.01 \\
\hline ICU care & 00 & $7 \%$ & 0.012 \\
\hline Bladder injury & $2 \%$ & $6 \%$ & 0.67 \\
\hline $\begin{array}{l}\text { Uterine incision } \\
\text { extension }\end{array}$ & $4 \%$ & $7 \%$ & 0.53 \\
\hline
\end{tabular}


Among intraoperative complication, It was observed that women who underwent second stage caesarean section had PPH during the procedure in $21 \%$ cases, out of which $16 \%$ cases were due to Atonic PPH and rest $5 \%$ were due to traumatic PPH. Blood transfusion was done in all women $(21 \%)$ who had PPH and $7 \%$ of them were shifted to ICU for intensive monitoring. While in group I, only $9 \%$ women had $\mathrm{PPH}, 11 \%$ required blood transfusion and none of them were admitted to ICU. Thus, incidence of $\mathrm{PPH}$, blood transfusion and ICU admission was significantly higher in group II than in group I. Although overall incidence of bladder injury was low, but was seen more often in group II $(6 \%)$ than in group I $(2 \%)$, however difference was not statistically significant. Extension of uterine incision was found in $7 \%$ women in group II and $4 \%$ women in group I, difference being statistically insignificant.

Table 3: Comparison of Postoperative maternal complications associated with first stage caesarean section (group I) and second stage caesarean section (group II).

\begin{tabular}{|llll|}
\hline $\begin{array}{l}\text { Post-operative } \\
\text { complications }\end{array}$ & $\begin{array}{l}\text { Group I } \\
\text { (\% of } \\
\text { women) }\end{array}$ & $\begin{array}{l}\text { Group II } \\
(\% \text { of } \\
\text { women) }\end{array}$ & P value \\
\hline Fever & $19 \%$ & $38 \%$ & $<0.001$ \\
\hline Wound sepsis & $19 \%$ & $28 \%$ & 0.012 \\
\hline Paralytic ileus & $05 \%$ & $29 \%$ & $<0.05$ \\
\hline $\begin{array}{l}\text { Prolonged } \\
\text { catheterisation }\end{array}$ & $38 \%$ & $90 \%$ & $<0.001$ \\
\hline Resuturing & $11 \%$ & $15 \%$ & 0.142 \\
\hline $\begin{array}{l}\text { Prolonged hospital } \\
\text { stay (7-15 days) }\end{array}$ & $13 \%$ & $20 \%$ & 0.05 \\
\hline
\end{tabular}

Among post-operative complications, in group II, prolonged bladder catheterisation was done in $90 \%$ of women and $38 \%$ of them had postpartum fever. Wound sepsis occurred in $28 \%$ women in group II, of which secondary resuturing was done in $15 \%$ of cases. Because of these postoperative complications, $20 \%$ of women in group II had to stay in hospital for prolonged time (7-15 days).

While in group I, prolonged bladder catheterisation, postpartum fever and wound sepsis was observed in 38\%, $19 \%$ and $19 \%$ of women respectively. Secondary resuturing was done in $11 \%$ cases and $13 \%$ women had prolonged hospital stay. A significant difference was found in incidence of all of the postoperative maternal complications except secondary resuturing among the two groups.

\section{Fetal complications}

Table 4 shows the fetal complications in group I and group II. Babies with low Apgar score, cord blood acidosis and need of resuscitation were significantly higher in group II $(7.3 \%, 7.3 \%$ and $36.3 \%$ respectively) than in group I (4\%, $4 \%$ and $16 \%$ respectively). $36.3 \%$ babies in group II and $28 \%$ in group I required admission to NICU, however difference was statistically insignificant Average birth weight of babies was significantly higher in group II $(2.8 \mathrm{~kg})$ than in group I $(2.6 \mathrm{~kg})$. Number of perinatal deaths was $12(3.7 \%)$ in group II, while in group I, no perinatal death was observed.

Table 4: Comparison of fetal complications associated with first stage caesarean section (group I) and second stage caesarean section (group II).

\begin{tabular}{|llll|}
\hline Fetal complications & $\begin{array}{l}\text { Group I } \\
(\% \text { of } \\
\text { women) }\end{array}$ & $\begin{array}{l}\text { Group II } \\
(\% \text { of } \\
\text { women) }\end{array}$ & $\begin{array}{l}\text { P } \\
\text { value }\end{array}$ \\
\hline Mean birth weight & $2.6 \mathrm{~kg}$ & $2.8 \mathrm{~kg}$ & 0.01 \\
\hline Cord blood $\mathrm{Ph}<7$ & $4 \%$ & $7.3 \%$ & 0.03 \\
\hline Low apgar score $(<7)$ & $4 \%$ & $7.3 \%$ & 0.03 \\
\hline Need of resuscitation & $16 \%$ & $36.3 \%$ & 0.014 \\
\hline Admission to NICU & $28 \%$ & $36.3 \%$ & 0.067 \\
\hline Perinatal death & 00 & $3.7 \%$ & 0.012 \\
\hline
\end{tabular}

\section{DISCUSSION}

In our study, relatively high rate of caesarean section (17.9\%) was observed. In study by Umbeli et al, higher caesarean rate of $28.8 \%$ was observed. ${ }^{5}$ However, WHO had quoted average caesarean rate to be in range of 5$15 \%$. This high rate of caesarean section in current study is because of the fact that our hospital is a tertiary referral hospital where all emergency cases are dealt.

In our study, most of the women who underwent second stage caesarean section were young ( $<25$ years) $(63 \%)$ and primigravida $(80 \%)$. In the study by Malathi et al, most of women were between 21-30 years of age (58\%) and primigravida $(72 \%) .{ }^{6}$ Higher rate of second stage caesarean section in young primigravida woman was probably due to higher incidence of rigid perineum, fetopelvic disproportion and uterine inertia.

The most common indication of first stage caesarean section was fetal distress while of second stage caesarean section was deep transverse arrest (53\%) and feto-pelvic disproportion (47\%). In study by Belay et al also, the most common indications of first stage caesarean section was fetal distress $(37.8 \%)$ and second stage caesarean section was cephalopelvic disproportion $(48.5 \%)^{7}$

Average operative time to perform second stage caesarean section was 81 minutes. However, in study conducted at tertiary hospital in South Africa, Govender et al found that mean operative time taken to perform second stage caesarean section was 41.6 minutes. $^{8}$ Cebekulu et al also found significantly longer operative time in second stage caesarean section (45 minutes) than in first stage caesarean section (30 minutes), $\mathrm{p}$ value $<0.001$. $^{2}$ Prolonged operative time for conducting second stage caesarean section in our hospital as compared to other hospital (Specially in South Africa) is probably 
because of the different technique used for delivering head which is impacted deep in the pelvis during second stage. In South Africa, usually, baby is delivered as cephalic with help of assistant, who pushes the head from vagina. While in our institution, in such cases, Patwardhan technique is followed. ${ }^{3}$ In our study in $86 \%$ cases, baby was delivered by Patwardhan technique.

Among maternal complications, incidence of $\mathrm{PPH}$, need of blood transfusion and admission to ICU was found to be significantly higher in group II $(21 \%, 21 \%$ and $7 \%$ respectively) than in group I (9\%, $11 \%$ and $0 \%$ respectively). More number of women had bladder injury and extension of uterine incision in group II (6\% and $7 \%$ respectively) as compared to group I (2\% and $4 \%$ respectively), however difference was statistically insignificant. In study by Alexander et al, maternal composite index (including uterine atony, extension of uterine incision and bladder injury) was significantly high in woman undergoing caesarean section in second stage (odds ratio 1.21, 95\% confidence interval 1.07-1.37). ${ }^{8}$ However in study by Malathi et al, no significant difference was found among two groups for $\mathrm{PPH}$ and extension of uterine incision. ${ }^{4}$

Among post-operative complications, it was observed that postpartum fever, wound sepsis and prolonged catheterization was found in significantly higher number of women who underwent second stage caesarean section (38\%, 28\% and 90 respectively). Similarly in study by Malathi et al, the incidence of postpartum fever, wound infection and prolonged catheterizations was higher in women delivered by second stage caesarean section (p value $<0.002,<0.05$ and $<0.001$ respectively). ${ }^{6}$

In current study, birth weight at delivery was significantly higher in second stage caesarean section $(2.8$ $\mathrm{kg})$ as compared to first stage caesarean section $(2.6 \mathrm{~kg})$. Similar results were found in study by Malathi et al $(2.96$ $\mathrm{kg}$ in second stage caesarean section and $2.70 \mathrm{~kg}$ in first stage caesarean section). ${ }^{6}$ However in study by Victoria MA et al no statistically significant difference was found among the two groups. ${ }^{10}$

Neonatal complications including cord blood acidosis, low Apgar score, need of resuscitation and perinatal deaths was found significantly higher in second stage caesarean section $(7.3 \%, 7.3 \%, 36.3 \%, 3.7 \%$ cases respectively). Cebekulu et al also found more babies with hypoxic ischemic encephalopathy ( $p$ value 0.013), subaponeurotic haemorrhage ( $\mathrm{p}$ value 0.012 ) and admission to NICU ( $p$ value $<0.001$ ) following second stage caesarean section. ${ }^{2}$ However in study by Alexandar et al, neonatal composite index was not found to be significantly different among first stage and second stage caesarean section. ${ }^{9}$

\section{CONCLUSION}

Second stage caesarean section is associated with significant maternal and fetal morbidities. Hence, a senior obstetrician should be present at the time of decision making and Patwardhan technique can be used to deliver deeply impacted head during the procedure so as to reduce the complications.

Funding: No funding sources

Conflict of interest: None declared

Ethical approval: Not required.

\section{REFERENCES}

1. Moodley J, devjee J, Khedun SM, Esterhuizen T. Second stage caesarean deliveries: are maternal complications increased? South African Family Practice. 2009;51(4):328-31.

2. Cebekulu L, Buchmann EJ. Complications associated with caesarean section in the second stage of labor. Int J gynecol Obstet. 2006;95:110-4.

3. Khosla AH, Dahiya K, Sangwan K. Caesarean section in a wedged head. Indian Journal Medicine Science. 2015;57:187-91.

4. Patwardhan BD, Motashaw ND. Cesarian Section. J Obstet Gynecol India. 1957;8:1-15.

5. Umbeli T, Ismail S, Kunna A, Elmahgoub A, Nasar A, Abdalwahab R. Maternal and neonatal complications associated with caesarean section in the second stage of labour at Omdurman maternity hospital during 2012-2013. Merit Research Journal of Medicine and Medical Sciences. 2014;2:225-8.

6. Malathi J, Sunita V. Comparison of obstetric outcome between first and second stage caesarean section in rural tertiary hospital. International Journal of Pharmaceutical and Biomedical Research. 2012;3:222-5.

7. Belay T, Yusuf L, Negash S. A comparative study on first stage versus second stage caesarean section on maternal and perinatal outcome. Ethiop Med J. 2014;52:1-8.

8. Govender V, Panday M, Moodley J. Second stage caesarean section at a tertiary hospital in South Africa. J Maternal Fetal Neonatal Med. 2010;23:1151-5.

9. Alexander JM, leveno KJ, Rouse DJ, Landon MB, Sponge CY, Varner MW, et al. Comparison of maternal and infant outcomes from primary caesarean delivery during the second compared with first stage of labour. Obstet Gynecol. 2007;109:917-21.

10. Victoria MA, Colleen M, Thomas FB. Maternal and perinatal morbidity of caesarean delivery at full cervical dilatation compared with caesarean delivery in the first stage of labour. BJOG. 2005;112:986-90.

Cite this article as: Jain N, Lal P. A retrospective comparative study of feto-maternal outcome in first and second stage caesarean section. Int J Reprod Contracept Obstet Gynecol 2016;5:2282-6. 